\title{
Optimisation of Deep-Fat Frying of Plantain Chips (Ipekere) using Response Surface Methodology
}

\author{
Adeyanju $\mathrm{JA}^{1 *}$, Olajide $\mathrm{JO}^{1}$ and Adedeji $\mathrm{AA}^{2}$
}

${ }^{1}$ Department of Food Science and Engineering, Ladoke Akintola University of Technology, Ogbomoso, Oyo State, Nigeria

${ }^{2}$ Department of Biosystems and Agricultural Engineering, University of Kentucky, Lexington, KY, USA

\begin{abstract}
Deep-fat frying of plantain chips (ipekere) was investigated with the aim of predicting optimum operating conditions for plantain chips to minimize oil content in order to produce healthy products. The effect of frying temperature and time on moisture content, oil content, breaking force and colour difference of plantain chips was evaluated. Response surface methodology was used to analyze the results of the central composite design of the frying processes for the responses as a result of variation in the levels of frying temperature $\left(150^{\circ} \mathrm{C}-190^{\circ} \mathrm{C}\right)$ and frying time $(2-4 \mathrm{~min})$. Response surface regression analysis shows that responses were significantly $(p<0.05)$ correlated with frying temperature and time. Regression model was developed for the investigation of the effect of frying temperature and time on the responses. The polynomial regression models were validated with statistical tool whose values of coefficients of determination $\left(R^{2}\right)$ were $0.9949,0.9817,0.9709$ and 0.9966 for moisture content, oil content, breaking force and colour intensity, respectively. The optimum values of moisture content, oil content, breaking force and colour difference were $3.73 \%, 1.18 \%, 17.66 \mathrm{~N}$ and 65.53 respectively, at frying temperature of $183^{\circ} \mathrm{C}$ and frying time of 3 minutes. Therefore, frying conditions had a significant effect on the quality attributes of chips produced from plantain.
\end{abstract}

Keywords: Plantain chips; Deep-fat frying; Regression models; Texture and colour

\section{Introduction}

Plantain (Musa AAB) is one of the most important food crops in the world. It is a major source of carbohydrate, antioxidants and minerals like potassium and calcium and caters for the calorific needs of many people in developing countries [1,2]. Nigeria is one of the largest plantain producing countries in the world with an estimated production at 2,722,000 metric tons in 2009 and an average consumption level of $190 \mathrm{~kg} /$ person/year [3,4]. In spite of its prominence, the country does not feature among plantain exporting nations because it produces more for local consumption than for export. Plantain consumption has risen greatly in Nigeria in recent years because of the rapidly increasing urbanization and the great demand for easy and convenient foods by the non-farming urban populations. Besides being the staple for many people in more humid regions, it is a delicacy and flavoured snack for people even in other regions. Plantain chips called Ipekere in south western part of Nigeria. It can be produced from green and slightly ripen green plantain with yellow patch, and fried to almost bone dry with golden yellow colouration.

Deep-Fat Frying (DFF) is a multifunctional unit operation of food transformation that can be described as cooking of food by immersion in edible oil or fat at a temperature higher than the boiling point of water [5]. DFF can be considered as a high temperature and a short time process which involves both mass transfer, mainly represented by water loss and oil uptake, and heat transfer [6]. It is one of the major value addition processes for plantain which results in products with a unique flavour-texture combination $[7,8]$. The primary reason for the popularity of DFF foods may be the characteristics like soft, juicy interior as well as thick and crispy outer crust [9]. Texture, colour and oil content are the main quality parameters of fried products [10].

Response surface methodology (RSM) is a useful technique for optimisation studies. This is a collection of mathematical and statistical techniques that is useful for modeling and analysis in applications where a response is influenced by several factors [11]. RSM is important in designing, formulating, developing, and analyzing new scientific studies and products. The most common applications of RSM are in industrial, biological, clinical, social, food, physical and engineering sciences. Optimisation is therefore required to ensure rapid processing while maintaining optimum product quality especially in term of the quality characteristics. The quality attributes for frying of food materials may include moisture content, oil content, breaking force and colour parameters while the process parameters to be optimised include frying temperature and time.

Most published studies on plantain over the years have dealt primarily with final product quality and physico-chemical changes in the oil medium during frying [12-15] and none of these reports have particularly optimised frying conditions to obtain fried plantain chips of acceptable quality attributes. However, there is little or no published work on statistical approach in RSM during DFF of plantain chips experiment for obtaining optimum conditions for quality characteristics of plantain. Therefore, the objective of this work was to optimize the DFF conditions with respect to quality attributes like moisture and oil contents, breaking force and colour parameters.

\section{Materials and Methods}

Matured plantain (Musa paradisiacal AAB) fruits harvested at green stage were procured from a local farm in Ogbomoso, South West Nigeria. Plantains were identified in the Department of Crop and Environmental Protection, LAUTECH, Oyo State, Nigeria. Plantains were washed with clean water, peeled manually and were cut into $2 \mathrm{~mm}$ thick slices using a stainless steel knife and a slicer. Refined vegetable oil

*Corresponding author: Adeyanju JA, Department of Food Science and Engineering Ladoke Akintola University of Technology, Ogbomoso, Oyo State, Nigeria, Tel: +2347087521919; E-mail: biodunjames24@yahoo.com

Received April 14, 2016; Accepted May 02, 2016; Published May 09, 2016

Citation: Adeyanju JA, Olajide JO, Adedeji AA (2016) Optimisation of Deep-Fat Frying of Plantain Chips (Ipekere) using Response Surface Methodology. J Food Process Technol 7: 584. doi:10.4172/2157-7110.1000584

Copyright: (C) 2016 Adeyanju JA, et al. This is an open-access article distributed under the terms of the Creative Commons Attribution License, which permits unrestricted use, distribution, and reproduction in any medium, provided the original author and source are credited. 
(Devon King's ${ }^{\mathbb{R}}$ ) obtained from Ace Supermarket, Ogbomoso was used as the frying medium in the deep-fat frying process.

\section{Frying Operation}

Frying was carried out in a deep-fat fryer (model MC-DF 1031, Cool Touch deep fryer, General Electric, Hong Kong, China) adapted with a PID temperature controller to maintain the set frying temperature within $\pm 1^{\circ} \mathrm{C}$. The fryer was filled with $2.5 \mathrm{~L}$ of oil and equipped with a 2 $\mathrm{kW}$ electric heater. Plantain slices to oil ratio was kept at 1:10 was used. The oil was preheated prior to frying and discarded after $2 \mathrm{~h}$. Before each frying test, the oil level was checked and replenished as required. Samples were fried at temperatures $150^{\circ} \mathrm{C}, 160^{\circ} \mathrm{C}, 170^{\circ} \mathrm{C}, 180^{\circ} \mathrm{C}$ and $190^{\circ} \mathrm{C}$, for $120,150,180,210$ and 240 seconds. After frying, excess oil was removed by shaking the baskets manually and the chips were placed on a rack to cool. Samples were stored in sealed, low density polyethylene bags and kept at room temperature until analyses were performed.

\section{Experimental Design}

Central composite of RSM for a two-variable experimental design was employed [11]. The independent factors considered were frying temperature $\left(\mathrm{X}_{1}: 150^{\circ} \mathrm{C}, 160^{\circ} \mathrm{C}, 170^{\circ} \mathrm{C}, 180^{\circ} \mathrm{C}\right.$ and $\left.190^{\circ} \mathrm{C}\right)$ and time $\left(\mathrm{X}_{2}\right.$ : 2, 2.5, 3.0, 3.5 and $4.0 \mathrm{~min}$ ) while the dependent factors were moisture content, oil content, breaking force and colour difference $(\Delta \mathrm{E})$ (Table 1$)$.

\section{Quality characteristics determination}

Moisture content: Five gram was weighed into a pre-weighed moisture dish. The dish plus sample taken was transferred into the oven pre-set at $105^{\circ} \mathrm{C}$ to dry to a constant weight for 24 hours overnight. At the end of the 24 hours, the dish plus sample was removed from the oven and transferred to desiccator, cooled for 30 minutes and weighed [16].

Oil content: Oil content was determined according to method described by AOAC [16] using soxhlet extraction. Fried samples were ground using a grinder. Five gram of sample was weighed into thimbles for fat extraction in a solvent extractor using petroleum ether. Fat content was determined as the ratio of the mass of extracted fat and dry matter of the sample.

Breaking force: The texture (breaking force) of the chips was determined using a universal testing machine (model M500,
Testometric AX, Rochdale, Lancashire, England) equipped with a 50 $\mathrm{kN}$ load cell. Fried plantain chips of uniform sizes were selected and then placed on a metal support with jaws at a distance of about $25 \mathrm{~mm}$. They were pressed in the middle with a cylindrical flat end plunger (70 $\mathrm{mm}$ diameter) at a speed of $2.5 \mathrm{~mm} / \mathrm{min}$. The measurement was recorded by a computer connected directly to the equipment. The breaking force $(\mathrm{N})$ interpreted as crispness was obtained as the peak force from the force-deformation curve [17].

Colour: Colour parameters lightness $\left(L^{*}\right)$, redness $\left(a^{*}\right)$ and yellowness $\left(b^{\star}\right)$ were measured using a colorimeter (Colour Tec-PCM, Hunterdon, NJ) as described by Krokida et al. [18]. The instrument was standardized and the samples were placed in the sample holder. Samples were scanned at different locations to determine $\left(L^{*}, a^{*}\right.$ and $\left.b^{\star}\right)$ parameters. Colour difference $(\Delta \mathrm{E})$ was calculated according to the equation:

\section{Colour difference}

$($ Hunter $\Delta \mathrm{E})=\left[\left(L-L_{\text {ref }}\right)^{2}+\left(a-a_{\text {ref }}\right)^{2}+\left(b-b_{\text {ref }}\right)^{2}\right]^{1 / 2}$

Where $\mathrm{L}_{\mathrm{ref}}, \mathrm{a}_{\mathrm{ref}}$ and $\mathrm{b}_{\mathrm{ref}}$ were the $\mathrm{L}$, $\mathrm{a}$ and $\mathrm{b}$ values of fresh plantain slices which were used as references.

\section{Statistical analysis}

All data were analyzed using the Design-Expert Version 6.0.8 (State-ease software). Regression analysis and analysis of variance (ANOVA) were conducted by fitting the equation to the experimental data to determine the regression coefficients and statistical significance of model terms. The significance of the model terms was assessed by F-ratio at a probability $\mathrm{p}<0.05$. Model adequacies were determined using model analysis, lack of fit test and coefficient of determination $\left(\mathrm{R}^{2}\right)$.

\section{Optimisation procedure}

Numerical optimisation was performed using Design Expert software V 6.0.8. Multiple responses were optimised simultaneously through the use of a desirability function that combines all the responses into one measurement. The method finds operating conditions (combination of independent variables) that maximizes the desirability function. The constraints were set to get the value of a variable for an optimum response (a minimum and maximum level must be provided for each variable included). The optimisation of the

\begin{tabular}{|c|c|c|c|c|c|c|c|c|}
\hline \multirow[t]{2}{*}{ Run } & \multicolumn{2}{|c|}{ Coded } & \multicolumn{2}{|c|}{ Actual } & \multicolumn{4}{|c|}{ Responses } \\
\hline & $x_{1}$ & $x_{2}$ & $x_{1}$ & $X_{2}$ & MC (\%) & OC (\%) & BF (N) & $\Delta \mathbf{E}$ \\
\hline 1 & -1.0 & -1.0 & 190 & 4 & 3.67 & 1.22 & 21.41 & 34.56 \\
\hline 2 & 1.0 & -1.0 & 170 & 4 & 3.69 & 1.20 & 15.97 & 55.89 \\
\hline 3 & -1.0 & 1.0 & 180 & 3 & 3.77 & 1.20 & 15.75 & 51.39 \\
\hline 4 & 1.0 & 1.0 & 170 & 3.5 & 3.5 & 1.19 & 17.78 & 52.64 \\
\hline 5 & 0.0 & 1.414 & 190 & 2 & 3.76 & 1.22 & 24.90 & 56.80 \\
\hline 6 & 0.0 & -1.414 & 150 & 4 & 4.37 & 1.14 & 24.11 & 66.99 \\
\hline 7 & 1.414 & 0.0 & 160 & 3.5 & 4.32 & 1.18 & 18.59 & 60.24 \\
\hline 8 & -1.414 & 0.0 & 170 & 3 & 3.69 & 1.20 & 15.97 & 55.89 \\
\hline 9 & 0.0 & 0.0 & 180 & 2.5 & 3.91 & 1.21 & 18.88 & 54.55 \\
\hline 10 & 0.0 & 0.0 & 190 & 3 & 3.86 & 1.20 & 15.67 & 47.73 \\
\hline 11 & 0.0 & 0.0 & 170 & 3 & 4.06 & 1.19 & 22.40 & 49.19 \\
\hline 12 & 0.0 & 0.0 & 170 & 2 & 4.19 & 1.19 & 17.78 & 52.64 \\
\hline 13 & 0.0 & 0.0 & 170 & 3 & 4.02 & 1.22 & 23.01 & 56.42 \\
\hline
\end{tabular}


DFF process was aimed at finding the levels of frying temperature and time, which could minimize the moisture content, oil content, breaking force and moderate colour.

\section{Results and Discussion}

\section{Estimation of the model parameters for plantain chips (Ipekere)}

The experimental data and their corresponding responses are shown in Table 1. Multiple regression and correlation analysis are used as tools for assessment of the effects of two or more independent variables on the dependent variables. The coefficients of determination $\left(\mathrm{R}^{2}\right)$ for moisture content, oil content, breaking force and colour are $0.9647,0.9844,0.9303$ and 0.9773 , respectively. These values are quite high for response surfaces and indicated that the fitted quadratic models accounted for more than $95 \%$ of the variance in the experimental data, which were found to be highly significant. The only regression coefficients significant at $95 \%$ levels according to $\mathrm{p}$-values were selected for developing the models (Table 2).

\section{Adequacy test of the models for plantain chips}

The fitted models were tested for adequacy and consistency by analysis of variance (ANOVA). The results from the statistical analysis revealed that the F-value for moisture content (38.21), oil content (88.19), breaking force (18.69) and colour difference (129.08) were significant at the $95 \%$ confidence level. Analysis of variance for response surface quadratic models of plantain chips is shown in Table 2. The empirical models obtained for the quality characteristics of plantain chips are stated as equations 1 to 4 . Quadratic model was found to satisfactorily explain the relationship for moisture content, oil content and breaking force while 2FI model was used to represent the relationship between colours of ipekere as affected by frying conditions. The model satisfied lack of fit test. Significant model terms at $p<0.05$ were frying temperature $\left(\mathrm{X}_{1}\right)$, frying time $\left(\mathrm{X}_{2}\right)$, second order of frying temperature and time $\left(\mathrm{X}_{1}^{2}, \mathrm{X}_{2}^{2}\right)$ and interaction of frying temperature and time $\left(\mathrm{X}_{1} \mathrm{X}_{2}\right)$. Therefore, the model is appropriate for predicting moisture content, oil content, breaking force and colour as influenced by frying temperature and time.

\section{Effect of Variables on the Responses}

\section{Moisture content}

\begin{tabular}{|c|c|c|c|c|c|c|}
\hline Responses & Sources of & DF & Sum of & \multicolumn{3}{|c|}{ Mean } \\
\cline { 6 - 7 } & Variation & & Squares & Squares & F-value & $\mathbf{R}^{\mathbf{2}}$ \\
\hline MC & Regression & 5 & 0.650 & 0.130 & 38.211 & 0.9647 \\
\hline & Residual & 7 & 0.023 & 0.003 & & \\
\hline & Total & 12 & 0.674 & & & \\
\hline OC & Regression & 5 & 0.005 & 0.001 & 88.194 & 0.9844 \\
\hline & Residual & 7 & $9.01 \mathrm{E}-05$ & $1.29 \mathrm{E}-05$ & & \\
\hline & Total & 12 & 0.005 & & & \\
\hline BF & Regression & 5 & 125.966 & 25.193 & 18.695 & 0.9303 \\
\hline & Residual & 7 & 9.433 & 1.347 & & \\
\hline & Total & 12 & 135.399 & & & \\
\hline$\Delta \mathrm{E}$ & Regression & 5 & 660.2538 & 220.084 & 129.08 & 0.9773 \\
\hline & Residual & 7 & 675.599 & & & \\
\hline & Total & 12 & 0.650 & 0.130 & 38.211 & \\
\hline & & & & & & \\
\hline
\end{tabular}

Where: $\mathrm{MC}=$ Moisture content, $\mathrm{OC}=$ Oil content, $\mathrm{BF}=$ Breaking force and $\Delta \mathrm{E}=$ Colour difference

Table 2: Analysis of variance for the responses.
Equation 2 indicates that at linear level, temperature and time had negative effect on the moisture content. At quadratic level, all the variables had positive effect on the moisture content, while interaction between temperature and time had negative effect. Effect of moisture content with frying temperature and time are shown in Figure 1. Significant interaction suggests that the level of one of the interaction variables can be increased while that of other decreased for constant value of the response. Shyu and Hwang [19] reported that the unbound water in the fried food can be rapidly removed when the oil temperature reaches the boiling point of water. The effects of frying temperature and time were significant $(\mathrm{p}<0.05)$ on the moisture content. Response plot (Figure 1) revealed that the rate of moisture loss in plantain chips increased by increasing the frying temperature and time. The moisture changes during frying showed the typical progressive decrease with increasing frying time. The result obtained was similar to the findings of $[20,21]$ on French fries and chicken meat respectively.

$$
\begin{aligned}
& \mathrm{MC}=33.51-0.31 \mathrm{X}_{1}-2.11 \mathrm{X}_{2}+8.91 \mathrm{E}-004 \mathrm{X}_{1}^{2}+0.25 \mathrm{X}_{2}^{2}-2.73 \mathrm{E}-003 \mathrm{X}_{1} \mathrm{X}_{2} \\
& \mathrm{OC}=1.01+5.87 \mathrm{E}-003 \mathrm{X}_{1}-0.24 \mathrm{X}_{2}-2.32 \mathrm{E}-005 \mathrm{X}_{1}^{2}+9.48 \mathrm{E}-003 \mathrm{X}_{2}^{2}+9.98 \mathrm{E}-004 \mathrm{X}_{1} \mathrm{X}_{2} \\
& \mathrm{BF}=322.02-2.82 \mathrm{X}_{1}-34.94 \mathrm{X}_{2}+7.79 \mathrm{E}-003 \mathrm{X}_{1}^{2}+4.87 \mathrm{X}_{2}^{2}-0.02 \mathrm{X}_{1} \mathrm{X}_{2} \\
& \Delta \mathrm{E}=-70.18+0.78 \mathrm{X}_{1}+64.40 \mathrm{X}_{2}-0.39 \mathrm{X}_{1} \mathrm{X}_{2}
\end{aligned}
$$

\section{Oil content}

As shown in Equation 3, at linear level, temperature and time had negative effect on the oil content. At quadratic level, temperature had negative effect and time had positive effect, while the interaction between temperature and time had positive effect on the oil content. Significant interaction suggests that the level of one of the interaction variables can be increased while that of other decreased for constant value of the response. The relationship of oil content with frying temperature and time are shown in Figure 2. The increased oil absorption during deep frying of plantain may be accredited to changes in porosity and molecular size redistribution. The oil content in fried products needs to be optimised because it affects the texture and appearance of the chips [22]. The final oil content of the chips is affected by the plantain's physicochemical characteristics and the processing conditions. Moreover, oil content in a product can depend on the frying temperature, time as well as moisture content [23-25]. The result obtained was similar to the findings of [26] who reported increase in fat content at longer frying time.

\section{Breaking force}

Breaking force was used to represent the crispness of fried plantain chips. Frying temperature and time had negative linear effect on the crispness of the chips. At quadratic level, temperature had negative effect and time had a significant positive effect, while interaction between temperature and time had negative effect on the crispness. The interaction effect of temperature and time on crispness is shown in Figure 3. As shown in Equation 4, at the two independent variables, second order derivatives and interactions between the variables are significant. Results showed that the effects of temperature were significant $(\mathrm{p}<0.05)$ on the crispness of the plantain chips. As temperature of frying increases, the rate of moisture removal becomes faster, thus favoring the frying process. The breaking force of the chips decreases as frying temperature and time increases. Crispness of chips is a vital measure that determines the consumers' acceptance [27]. It is the most important textural attribute which denotes freshness and high quality. The peak compression force increased with increasing frying 
Citation: Adeyanju JA, Olajide JO, Adedeji AA (2016) Optimisation of Deep-Fat Frying of Plantain Chips (Ipekere) using Response Surface Methodology. J Food Process Technol 7: 584. doi:10.4172/2157-7110.1000584

MC
$X=A: T e m p e r a t u r e$

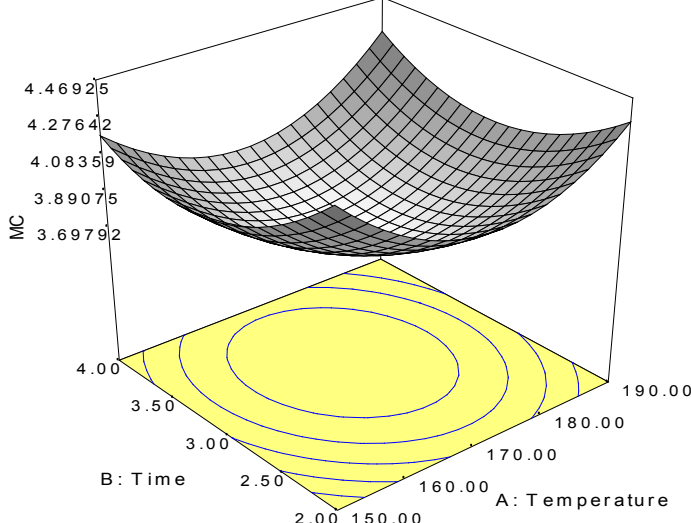

Figure 1: Response surface plot showing the effect of frying temperature and time on moisture content of plantain chip.
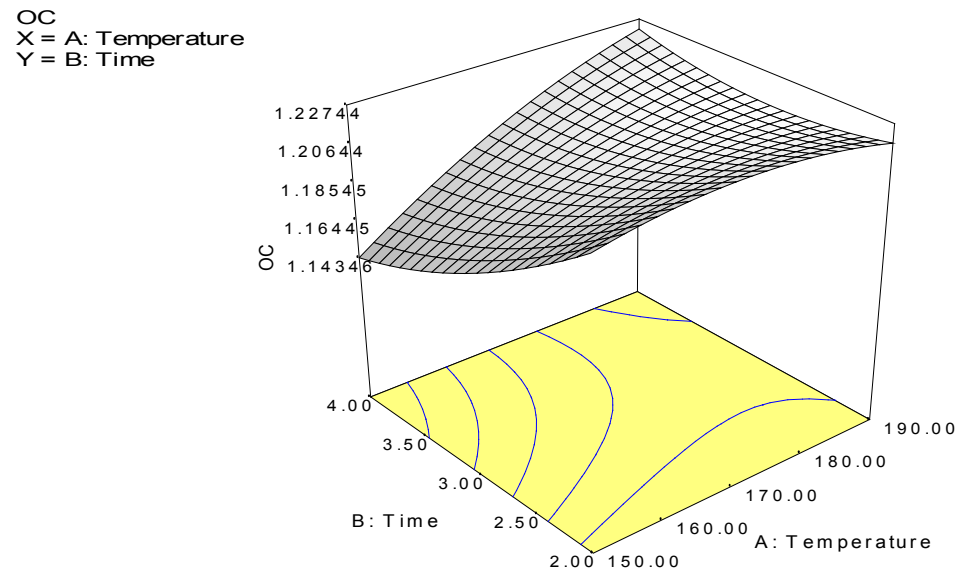

Figure 2: Response surface plot showing the effect of frying temperature and time on oil content of plantain chip.
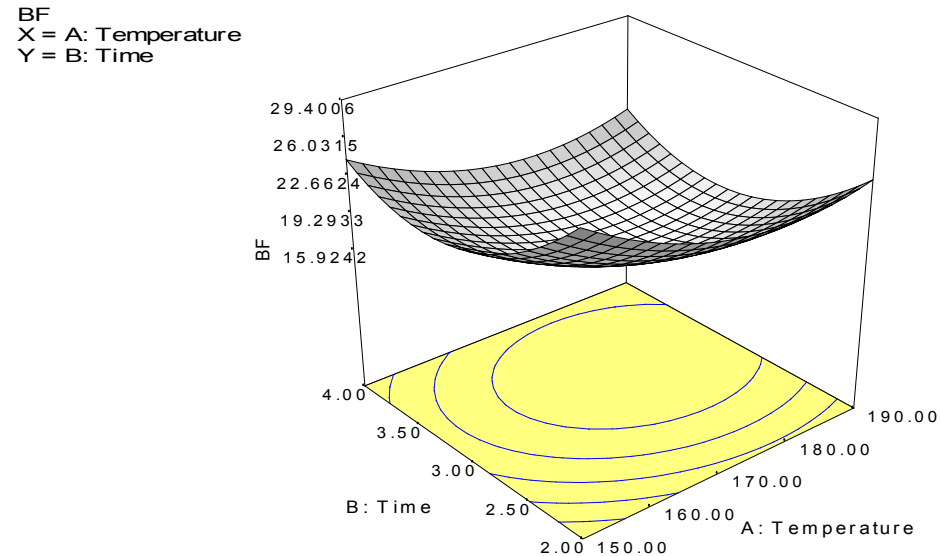

Figure 3: Response surface plot showing the effect of frying temperature and time on breaking force of plantain chip. 


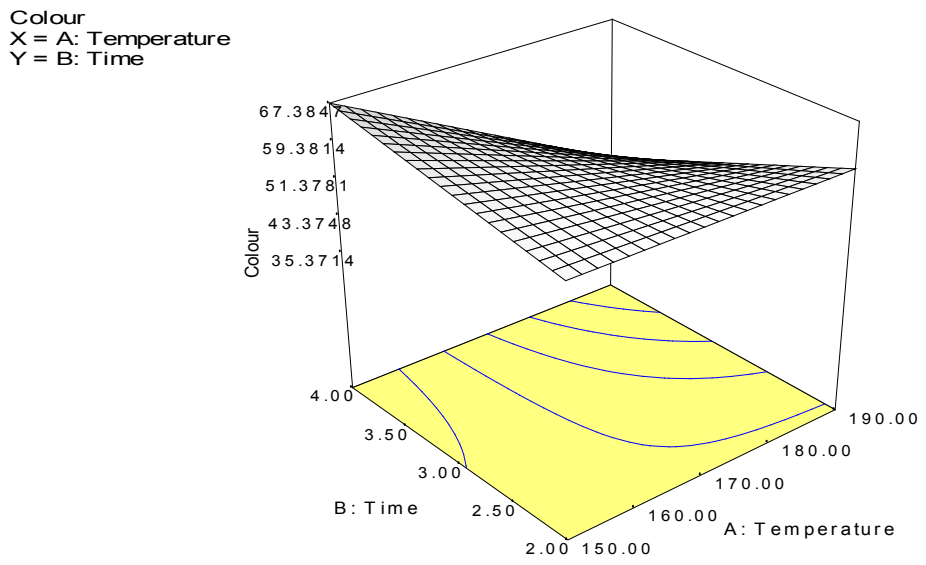

Figure 4: Response surface plot showing the effect of frying temperature and time on colour difference of plantain chip.

conditions or when the initial plantain moisture content was lower. The result obtained was in agreement with the findings that the hardness of fried chickpea flour-based snack increased at lower moisture content of the pre-fried product [28].

\section{Colour difference}

The effect of interaction of temperature and time on colour intensity is shown in Figure 4. As reflected in Equation 5, at linear level, temperature had negative effect; time had a significant positive effect on the colour difference. At quadratic level, temperature had positive effect and time had negative effect, while interaction between temperature and time had negative effect on the colour. The colour intensity of plantain chips decreased progressively as the frying temperature and time increased (Figure 4). This indicates that higher $\Delta \mathrm{E}$ values will lead to lower colour quality on the surface of plantain chips. It was observed that an increase of temperature led to a significant formation of brown products. The modification in fried plantain colour is mainly due to the effect of temperature on heat-sensitive compounds such as carbohydrates, proteins and vitamins, which cause colour degradation during drying process. The formation of brown compounds in plantain may be related to both enzymatic and essentially non-enzymatic (maillard reaction) reactions [29]. This result is similar to the report of [30] that colour changes also indicated more mallard reaction with frying time which utilized the abundant reducing sugars in plantain.

\section{Optimisation of the frying process}

RSM was used for the optimisation of DFF of plantain chips and for understanding the factors affecting the frying process. Based on response surface regression analysis of each model, the models (MC, $\mathrm{OC}, \mathrm{BF}$ and $\triangle \mathrm{E}$ ) were useful for indicating the direction in which to change variables in order to minimize moisture content, fat content and texture (breaking force) and moderate colour. The desirability lies between 0 and 1 ; and it represents the closeness of a response to its ideal value. Desirability of the solution was 0.76 . Three possible optimum solutions were found with desirability ranging from 0.75 to 0.79 . The best of the three conditions was frying at $183.61^{\circ} \mathrm{C}$ for 3.19 minutes which gave $3.73 \% \mathrm{MC}, 1.18 \% \mathrm{OC}, 17.66 \mathrm{~N}$ crispness and 65.53 colour.

\section{Conclusion}

The RSM was effectively used to investigate the effects of frying temperature and time on the quality characteristics of plantain chips.
The optimum values for moisture content, oil content, breaking force and colour difference from the surface plot was 3.73\%, $1.18 \%$, $17.66 \mathrm{~N}$ and 65.53 , respectively. Therefore, temperature and time were determined to have significant effect on the quality attributes of plantain chips. Thus, the optimized frying conditions were able to produce high quality plantain chips.

\section{References}

1. Kanazawa K, Sakakibara H (2000) High content of dopamine, a strong antioxidant, in Cavendish banana. J Agric Food Chem 48: 844-848.

2. Mohapatra D, Mishra S, Sutar N (2010) Plantain and its byproduct utilization: An overview. J Sci Ind Res 69: 323-329.

3. FAO (2011) Production, commodity by country; FAOSTAT Data. Food and Agriculture Organisation of the United Nations, Rome.

4. FAO (2013) Food and Agriculture Organization of the United Nations. Crop yield.

5. Farkas BE, Hubbard LJ (2000) Analysis of heat transfer during immersion frying. Dry Technol 18: 1269-1285.

6. Vitrac O, Dufour D, Trystram G, Raoult-Wack A (2002) Characterization of heat and mass transfer during deep-fat frying and its effect on cassava chip quality. J Food Eng 53: 161-176.

7. Mellema M (2003) Mechanism and reduction of fat uptake in deep-fat fried foods. Tr Food Sci Technol 14: 364-373.

8. Pedreschi $F(2012)$ Frying of potatoes: Physical, chemical and microstructural changes. Dry Technol 30: 707-725.

9. Garcia MA, Ferrero C, Bertola N, Martino M, Zaritzky N (2002) Edible coatings from cellulose derivatives to reduce oil uptake in fried products. Inn Food Sci Emerg Technol 3: 391-397.

10. Hindra F, Baik OD (2006) Kinetics of quality changes during food frying. Crit Rev Food Sci Nutr 46: 239-258.

11. Montgomery DC (2005) Design and analysis of experiments: Response surface method and designs. John Wiley \& Sons, Inc, New Jersey, USA.

12. Onyejegbu CA, Olorunda AO (1995) Effects of raw materials, processing conditions and packaging on the quality of plantain chips. J Sci Food Agri 68: 279-283.

13. Akubor PI, Adejo EE (2000) Physicochemical, microbiological and sensory changes in stored plantain chips. Plant Foods Hum Nutr 55: 139-146.

14. Agunbiade SO, Olanlokun JO, Olaofe OA (2006) Quality of chips produced from rehydrated dehydrated plantain and banana. Pak J Nutri 5: 471-473.

15. Avallone S, Rojas-Gonzalez JA, Trystram G, Bohuon P (2009) Thermal sensitivity of some plantain micronutrients during deep-fat frying. J Food Sci 74: C339-347. 
Citation: Adeyanju JA, Olajide JO, Adedeji AA (2016) Optimisation of Deep-Fat Frying of Plantain Chips (Ipekere) using Response Surface Methodology. J Food Process Technol 7: 584. doi:10.4172/2157-7110.1000584

16. AOAC (2000) Official methods of analysis, Association of Official Analytical Chemists. Virginia, USA.

17. DaSilva PF, Moreira RG (2008) Vacuum frying of high-quality fruit and vegetable-based snacks. LWT-Food Sci Technol 41: 1758-1767.

18. Krokida MK, Oreopoulou V, Maroulis ZB, Marinos-Kouris D (2001) Colour changes during deep-fat frying. J Food Eng 48: 219-225.

19. Shyu S, Hwang L (2001) Effects of processing conditions on the quality of vacuum fried apple chips. Food Res Int 34: 133-142.

20. Krokida MK, Oreopoulou V, Maroulis ZB, Marinos-Kouris D (2001) Effect of pre-drying on quality of french fries. J Food Eng 49: 347-354.

21. Kassama L, Ngadi M (2005) Pore development and moisture transfer in chicken meat during deep-fat frying. J Dry Technol 23: 907-923.

22. Dobarganes MC, Velasco J, Dieffenbache A (2000) Determination of pola compounds, polymerized and oxidized triacylglycerols, and diacylglycerols in oils and fats. Pure Appl Chem 72: 1563-1575.

23. Moreira RG, Sun X, Chen $Y$ (1997) Factors affecting oil uptake in tortilla chips in deep-fat frying. J Food Eng 31: 485-98.
24. Sharma SK, Mulvaney SJ, Rizvi SSH (2000) Frying of foods. In: Food Process Engineering Theory and Laboratory Experiments. Wiley, New York, NY.

25. Yagua CV, Moreira RG (2011) Physical and thermal properties of potato chips during vacuum frying. J Food Eng 104: 272-283.

26. Nantawan T, Phaisan W, Anuvat J, Chatlada K (2007) Optimisation of vacuum frying condition for shallot. Kas J Natur Sci 41: 338-342.

27. Setiady D, Tang J, Younce F, Swanson BA, Rasco BA, et al. (2009) Porosity colour, texture using microwave vacuum, heated air, and freeze drying. ASABE Appl Engi Agri 25: 719-724.

28. Debnath S, Bhat KK, Rastogi NK (2003) Effect of pre-drying on kinetics of moisture loss and oil uptake during deep fat frying of chickpea flour-based snack food. LWT - Food Sci Technol 36: 91-98.

29. Miranda M, Maureira H, Rodriguez K, Vega-Galvez A (2009) Influence of temperature on the drying kinetics, physicochemical properties, and antioxidant capacity of Aloe Vera (Aloe Barbadensis Miller) gel. J Food Eng 91: 297-304.

30. Onwuka GI, Onwuka ND (2005) The effects of ripening on the functiona properties of plantain and plantain based cake. Int J Food Prop 8: 1021-1026. 